\title{
Investigating the Impacts of Preoperative Steroid Treatment on Tumor Necrosis Factor-Alpha and Duration of Extubation Time underwent Ventricular Septal Defect Surgery
}

\author{
H. Hakan Poyrazoğlu' ${ }^{1}$ Zeynel Duman ${ }^{1}$, Şerafettin Demir ${ }^{2}$, M. Kemal Avşar ${ }^{3}$, Atakan Atalay ${ }^{1}$, Bahattin Çiftçi ${ }^{1}$, \\ Insan Bayraktar ${ }^{1}$, Funda Tor ${ }^{1}$
}

${ }^{1}$ Department of Cardiovascular Surgery, Çukurova University School of Medicine, Adana, Turkey
${ }^{2}$ Department of Cardiology, Adana State Hospital, Adana, Turkey
${ }^{3}$ Department of Cardiovascular Surgery, Medicana International Hospital, İstanbul, Turkey

Background: Cardiopulmonary bypass is known to cause inflammatory events. Inflammation occurs due to many known important biological processes. Numerous mechanisms are known to be responsible for the development of inflammatory processes. Currently, there are many defined mediators as a tumor necrosis factor- $\alpha(\mathrm{TNF}-\alpha)$ playing an active role in this process.

Aims: This research was to investigate the effects of preoperative steroid use on inflammatory mediator TNF- $\alpha$ and on time to extubation postoperatively in ventricular septal defect patients undergoing cardiopulmonary bypass surgery. Study Design: Controlled clinical study.

Methods: This study included 30 patients. These patients were assigned into two groups, each containing 15 patients. 5 micrograms $/ \mathrm{kg}$ methylprednisolone was injected intravenously 2 hours before the surgery to Group I, whereas there was no application to the patients in Group II. TNF- $\alpha(\mathrm{pg} / \mathrm{mL})$ level was measured in arterial blood samples obtained at four periods including: the preoperative period (Pre TNF); at the $5^{\text {th }}$ minute of cross-clamping (Per TNF); 2 hours after ter- mination of cardiopulmonary bypass (Post TNF); and at the postoperative 24th hours in cardiovascular surgery intensive care unit (Post $24 \mathrm{~h} \mathrm{TNF}$ ).

Results: The mean cross-clamp time was $66 \pm 40$ and $55 \pm 27$ minutes in Group I and Group II respectively. No significant difference was found between the groups in terms of cross-clamp time $(p>0.05)$. The mean time to extubation was $6.1 \pm 2.3$ hours in Group I and 10.6 \pm 3.4 hours in Group II. Group I extubation time was significantly shorter than Group II. Group I TNF- $\alpha$ levels at Post TNF and Post24h TNF was lower than Group II. These differences are also statistically significant $(\mathrm{p}<0.05)$.

Conclusion: There is a strong indication that preoperative steroid treatment reduced the TNF- $\alpha$ level together with shortens duration of postoperative intubation and positively contributes to extubation in ventricular septal defect patients operated in cardiac surgery with cardiopulmonary bypass. (ClinicalTrials.gov Identifier: TCTR20150930001) Keywords: Airway extubation, cardiopulmonary bypass, congenital heart defect, methylprednisolone, tumor necrosis factor- $\alpha$
Cardiopulmonary bypass is known to cause inflammatory events (1). Inflammation developed during pediatric heart surgery is associated with interaction of blood with foreign surface during cardiopulmonary bypass, ischemia-reperfusion injury, and temperature changes during heating and cooling periods and durations of these periods, endotoxins, and surgical trauma (2).
Inflammation is a defence mechanism developed by the organism against harmful agents. Inflammation may lead to multiple organ failure in the organism (3-4). Therefore, inflammation is one of the factors that influence morbidity and mortality rates. Inflammation that would occur particularly in the central nervous, respiratory and circulatory systems of

Address for Correspondence: Dr. H. Hakan Poyrazoğlu, Department of Cardiovascular Surgery, Çukurova University School of Medicine, Adana, Turkey 
patients undergoing cardiopulmonary bypass may appear in various clinical pictures. This may either be mild or lead to a more severe clinical condition. Inflammation after pediatric open heart surgery is a parameter affecting also duration of mechanical ventilatory support (5-6).

Cardiac operations with cardiopulmonary bypass cause a systemic inflammatory response that may result organ injury which lead to postoperative morbidity. An inflammatory response after open-heart surgery following to cardiopulmonary bypass, derived by complement activation (C3a, C4a, C5a, and $\mathrm{C} 5 \mathrm{~b}-9$ ), cytokine production and neutrophil sequestration in lungs can cause various complications. Cytokines which are protein in structure called pro-inflammatory mediators play a key role in this systemic inflammation. Cardiopulmonary bypass triggers plasma protein systems through contact, complement and fibrinolytic sytems, intrinsic and extrinsic coagulation, together with blood cells, including platelets, endothelial cells, lymphocytes, neutrophils and monocytes. It has also activation potential of stimulus for the release of proinflammatory cytokines, including TNF- $\alpha$, IL-1, IL-6, IL-8 and IL-10. These processes are responsible for the common complications of cardiopulmonary bypass, including bleeding thromboembolism, fluid retention, and temporary organ dysfunction (7-9).

There are many studies suggesting that steroidal drugs have anti-inflammatory effects by suppressing proinflammatory mediators (10-12). In the present study, preoperative steroid treatment reduce the level of TNF- $\alpha$ and the duration of postoperative mechanical ventilation who undervent ventricular septal defect surgery. Thus, the major hypothesis of this study was to investigate i) the preoperative steroid treatment who undervent ventricular septal defect surgery reduce the level of TNF- $\alpha$ and, ii) shortens extubation time for postoperative mechanical ventilation.

\section{MATERIALS AND METHODS}

\section{Clinical data}

These two groups included 30 patients undergoing surgery with cardiopulmonary bypass due to ventricular septal defect. These patients were assigned into two groups, first patient directly included in group one, second patient included in group two. Then chosen odd numbered patients were participated in group I and even numbered patients were participated in group II. Both group containing 15 patients. A signed informed consent form from patient's parents for each case was obtained. This work had been approved by the University Ethical Board. Exclusion criteria were recognized chromosomal anomalies, genetic syndromes, prior intracardiac surgery, complex heart disease or excessive pulmonary hypertension. All patients had a preoperative cardiac catheterization. Additionally, selection of the patients was based on the ratio of volume of pulmonary flow $(\mathrm{Qp})$ and systemic flow (Qs) for pulmonary tension:

$$
\mathrm{Qp} / \mathrm{Qs}=\left(\mathrm{Sat}_{\mathrm{AO}}-\mathrm{Sat}_{\mathrm{MV}}\right) /\left(\mathrm{Sat}_{\mathrm{LA}}-\mathrm{Sat}_{\mathrm{PA}}\right)
$$

Where $S a t_{\mathrm{AO}}$ is the aortic blood oxygen saturation, $S a t_{\mathrm{MV}}$ is the mixed venous blood oxygen saturation, $S a t_{\mathrm{LA}}$ is the left atrial blood oxygen saturation, and $S_{\mathrm{PA}}$ is the pulmonary artery blood oxygen saturation.

Thus, patients approximately with $2 \mathrm{Qp} / \mathrm{Qs}$ ratio were considered. Group I (n: 15) received methylprednisolone at a dosage of 5 micrograms/kg intravenously 2 hours (h) before surgery. On the other hand, Group II has not received methylprednisolone or placebo (n: 15) as this research was not designed as a clinical study. TNF- $\alpha(\mathrm{pg} / \mathrm{mL})$ level was measured in arterial blood samples obtained at the preoperative period (Pre TNF), at the $5^{\text {th }}$ min of cross-clamping (Per TNF), 2 hours after termination of cardiopulmonary bypass (Post TNF) and at the postoperative $24^{\text {th }}$ hours in cardiovascular surgery intensive care unit (Post $24^{\text {th }} \mathrm{TNF}$ ). Distribution of ventricular septal defect patient types in both groups was given in Table 1.

The extubation criterias are; weaning is completed; the patient is sufficiently awake with intact airway reflex, functional respiratory muscle and normal muscle strength, stable cardiovascular status, normal body temperature, manageable secretions. The negative inspiratory force is more than $-20 \mathrm{~cm} \mathrm{H}_{2} \mathrm{O}$, the vital capacity is greater than or equal to 10 $\mathrm{mL} / \mathrm{kg}$ and stable blood gas measurements include $\mathrm{PaO}_{2}>60$ $\mathrm{mmHg}$ or $\mathrm{SO}_{2}>95 \%, \mathrm{PaCO}_{2}<50 \mathrm{mmHg}, \mathrm{pH} 7.35$ - 7.45 (13). The standard application of this study was to extubate whole suitable patients. The final decision to implement extubation in the intensive care unit was made by the surgeon and physician in the final stage of the procedure. When the patient was breathing spontaneously with acceptable respiratory variables, then the patient was extubated, and oxygen was applied via a nasal cannula.

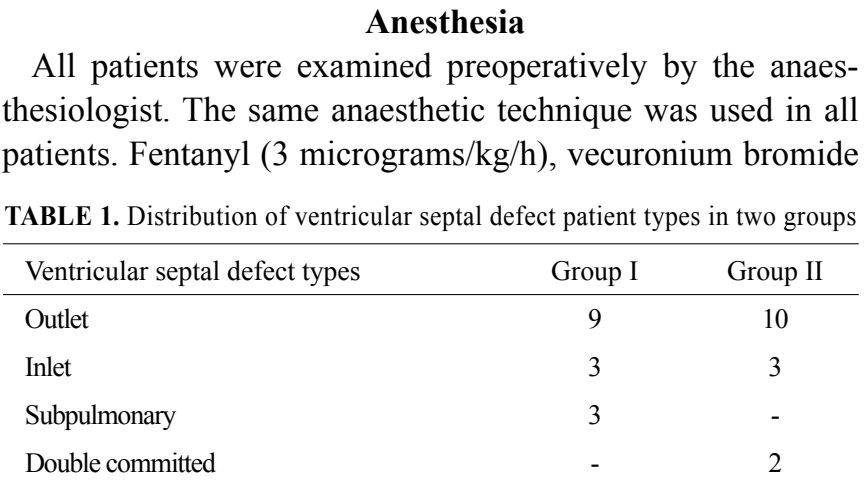


(intubating dose 0.10 milligram $/ \mathrm{kg}$, a continuous infusion of 1 micrograms $/ \mathrm{kg} / \mathrm{min}$ ) and inhalation agent (sevoflurane) were applied to the patients. However, vecuronium bromide was not applied to none of these two groups in last 45 minutes of the operation. Inhalation agent sevoflurane (\%0.5-2) was used while the patient was on cardiopulmonary bypass. Inotropic drugs (dopamine hydrochloride, dobutamine hydrochloride, milrinone lactate) were given if necessary. Children undergoing surgical repair of ventricular septal defect were received low-dose fentanyl ( 0.5 micrograms $/ \mathrm{kg} / \mathrm{h})$, during postoperative 12 hours.

\section{Cardiopulmonary bypass technique}

Standard non-pulsatile cardiopulmonary bypass was utilized, and the circuit primed with Plasmalyte A (Baxter Healthcare Corporation; Deerfield, IL, USA), and 1 unit of fresh-frozen plasma. Banked, packed red blood cells (PRBC) were added to achieve a hematocrit of approximately $28-30 \%$ during cardiopulmonary bypass. Moderate $\left(27^{\circ} \mathrm{C}\right.$ to $\left.30^{\circ} \mathrm{C}\right)$ hypothermia was employed, and myocardial preservation was obtained with cold blood cardioplegia at $20 \mathrm{~min}$. intervals. The $\mathrm{pH}$-stat regimen was used during cooling, and alpha-stat for rewarming. Protamine was given at $0.6: 1$ protamine to heparin ratio. Blood product transfusions following cardiopulmonary bypass were administered as necessary to achieve satisfactory haemostasis and a target haematocrit of $>30 \%$. Standard transatrial or transventricular closure of the ventricular septal defect was employed in all patients. The ascending aorta is used for arterial cannulation. Bicaval cannulation is used for venous cannulation. In order to accomplish venting the heart, we introduce a vent catheter to the left atrium through the right superior pulmonary vein.

\section{Postoperative care}

Standardized postoperative care was provided. Postoperative monitoring included continuous registration of heart rate and rhythm, arterial blood pressure, central venous pressure, diuresis, and blood gases. Dopamine in the dose of 3-5 micrograms $/ \mathrm{kg} /$ minute was given to the whole patients. However, high dose of dopamine ( $15 \mathrm{micrograms} / \mathrm{kg} /$ minute) during the first 24 hours of postoperative period was given to 2 and 1 patients with inlet ventricular septal defect in Group I and II respectively. Nitrogliserin with appropriate dose was given to the whole patients for peripheral vasodilatation. Furosemide infusion was given to the whole patients for 12 hours with the dose of $0.01 \mathrm{milligram} / \mathrm{kg} /$ hour. There were no postoperative infections observed. There were only two patients had urination difficulty temporarily however this was recovered short after. In this prospective study, physicians were not informed about steroid treatment to reduce variation in the extubation.
TABLE 2. Demographic characteristics of the patients

\begin{tabular}{|c|c|c|c|}
\hline Variables & $\begin{array}{c}\text { Grup I n: } 15 \\
\text { Mean } \pm \text { SD }\end{array}$ & $\begin{array}{c}\text { Grup II n: } 15 \\
\text { Mean } \pm \text { SD }\end{array}$ & $\mathrm{p}$ \\
\hline Age at operation, years & $2.3 \pm 1.5$ & $2.2 \pm 1.3$ & $0.608 \mathrm{a}$ \\
\hline Sex (female/male) & $7 / 8$ & $6 / 9$ & $0.565 b$ \\
\hline Body weight, $\mathrm{kg}$ & $14.1 \pm 8.3$ & $13.8 \pm 5.6$ & $0.601 \mathrm{a}$ \\
\hline Qp/Qs & $2.25 \pm 0.65$ & $2.30 \pm 0.76$ & $0.700 \mathrm{a}$ \\
\hline CPB time, minute & $90.2 \pm 42.2$ & $75.3 \pm 33.7$ & $0.465 \mathrm{c}$ \\
\hline Aortic cross-clampduration, minute & $66.3 \pm 40.9$ & $55.41 \pm 27.8$ & $0.567 \mathrm{c}$ \\
\hline Duration of intubation, hours & $6.1 \pm 2.4$ & $10.6 \pm 3.4$ & $0.001 \mathrm{c}$ \\
\hline \multicolumn{4}{|l|}{ Mean arterial blood pressure, $\mathrm{mm} \mathrm{Hg}$} \\
\hline Pre TNF & $61.8 \pm 18.3$ & $73.8 \pm 17.1$ & $0.805 \mathrm{a}$ \\
\hline Per TNF & $36.8 \pm 14.4$ & $43.6 \pm 16.2$ & $0.451 \mathrm{a}$ \\
\hline Post TNF & $87.6 \pm 13.6$ & $85.9 \pm 18.2$ & $0.860 \mathrm{a}$ \\
\hline Post 24h TNF & $84.9 \pm 11.5$ & $86.4 \pm 17.9$ & $0.900 \mathrm{a}$ \\
\hline \multicolumn{4}{|l|}{ Heart rate, beats/min } \\
\hline Pre TNF & $98.7 \pm 16.4$ & $96.4 \pm 11.7$ & $0.650 \mathrm{a}$ \\
\hline Per TNF & - & - & \\
\hline Post TNF & $125.1 \pm 10.8$ & $121.4 \pm 12.9$ & $0.708 \mathrm{a}$ \\
\hline Post 24h TNF & $107.5 \pm 19.9$ & $110.5 \pm 16.8$ & $0.654 \mathrm{a}$ \\
\hline \multicolumn{4}{|l|}{ Diuresis, $\mathrm{mL} / \mathrm{kg} / \mathrm{h}$} \\
\hline Pre TNF & $2.4 \pm 1.9$ & $2.1 \pm 2.1$ & $0.576 \mathrm{c}$ \\
\hline Per TNF & $4.4 \pm 2.2$ & $3.1 \pm 1.8$ & $0.431 \mathrm{c}$ \\
\hline Post TNF & $3.6 \pm 3.5$ & $3.8 \pm 4.0$ & $0.545 \mathrm{c}$ \\
\hline Post $24 \mathrm{~h}$ TNF & $3.4 \pm 2.8$ & $4.5 \pm 2.3$ & $0.398 \mathrm{c}$ \\
\hline Duration in ICU & $3 \pm 1$ & $4 \pm 1$ & $0.451 \mathrm{c}$ \\
\hline Duration in Hospital & $6 \pm 2$ & $7 \pm 2$ & $0.384 \mathrm{c}$ \\
\hline
\end{tabular}

TABLE 3. Mean tumor necrosis factor-alpha (TNF- $\alpha$ ) levels of Group I and Group II at Periods

\begin{tabular}{lccc}
\hline & $\begin{array}{c}\text { Group I } \\
\text { Median (Min-Max) }\end{array}$ & $\begin{array}{c}\text { Group II } \\
\text { Median (Min-Max) }\end{array}$ & p* \\
\hline Pre TNF & $0.6(0.1-2.8)$ & $0.75(0-5)$ & 0.318 \\
Per TNF & $1.4(0.2-21)$ & $6.2(0-18)$ & 0.770 \\
Post TNF & $0.6(0.1-15)$ & $6.95(0.54-38)$ & 0.003 \\
Post 24h TNF & $0.4(0-6.6)$ & $4.3(0.1-25)$ & 0.018 \\
& & & Power $=72.3 \%$ \\
$\mathrm{p}^{+}$ & 0.009 & 0.003 & \\
\hline * Mann Whitney test; + Repeated Measurement Analysis
\end{tabular}

\section{Laboratory tests}

For the analyses of serum TNF- $\alpha, 2 \mathrm{~mL}$ of arterial blood samples (for each analysis) were transferred to the laboratory in biochemistry tubes and analysed by micro-enzyme-linked immunosorbent assay (ELISA) method. 


\section{Statistical analysis}

Statistical analyses of data were performed by the Statistical Package for the Social Sciences version 19.0 (SPSS, Inc.; Chicago, IL, USA). Categorical variables were summarized as number and percentages, whereas continuous variables (such as time to extubation and total cross-clamp time) were summarized as mean standard deviation, median, and minimummaximum, where appropriate.

The normality of distribution for continuous variables was confirmed with the One Sample Kolmogorov test. Multivariate repeated measures analysis was used to compare the changes in continuous variables over time (Pre TNF, Per TNF, Post TNF and Post 24h TNF). In addition to analysing the changes in repeated measurements within the group, this method also analyses the difference between repeated measurements. The study observed power was obtained as $72.3 \%$ Chi-square test was used for comparison of gender by groups. The Mann-Whitney $U$ test was used for comparison of non-normally distributed data by groups. Thus, this test was not used to analyse the changes in time, it was only used to understand the differences of measurement values for two groups at any time period.

\section{RESULTS}

Demographic characteristics of the patients were given in Table 2. There were no significant statistically difference comparing the groups about variables such as age, sex, body weight, Qp/Qs, cardiopulmonary bypass time, aortic cross-clamp time, mean arterial blood pressure, heart rate, diuresis in Table 2. There was no significant difference between Groups I and II in terms of TNF- $\alpha$ levels at Pre TNF $(p=0.318)$ and Per TNF $(p=0.800)$ (Table 3). A significant difference was determined between Group I and II in terms of TNF- $\alpha$ levels at Post TNF $(p=0.003)$. There was also a significant difference between Groups I and II in terms of TNF- $\alpha$ levels at Post $24 h$ TNF $(p=0.18)$. As a result of repeated measures analysis, TNF- $\alpha$ level was increased initially then there was a decrease for both groups. These results were statistically significant. The significance level was set at $\mathrm{p}<0.05$ for all tests.

The mean time to extubation for Group I and Group II is presented in Table 2. The mean time to extubation was $6.13 \pm 2.35$ hours in Group I and 10.60 \pm 3.40 hours in Group II. A significant difference was found between the groups in terms of mean time to extubation $(\mathrm{p}=0.001)$.

There was no difference between both groups statistically about length of stay at the hospital $(p=0.384)$, although significant difference was found between two groups in terms of mean time to extubation $(\mathrm{p}=0.001)$.
There was a change in TNF $\alpha$ measurements for group I and II over time in the range of 0.009 and 0.003 respectively. TNF $\alpha$ measurements at per operative has the highest amongst others for group I, whereas per op and post op TNF alfa in group II significantly higher than others.

\section{DISCUSSION}

Cytokines consist of group of polypeptides derived by various cell types. There is an increasing attention on the functions of cytokines as a metabolic mediator. The cytokine response of patients operated cardiac surgery during cardiopulmonary bypass is well understood and managed by the proinflammatory cytokines IL- 6 , TNF- $\alpha$ and IL- 8 and the anti-inflammatory cytokine IL-10. The main source of these cytokines at cardiac ischemia during cardiopulmonary bypass is the myocardium. The occurrence of proinflammatory cytokines as a result of cardiopulmonary bypass increases the risk of harmful effects of cardiopulmonary bypass for myocardium. These mechanisms have strong relationship with ischemia-reperfusion of the myocardium and also other organs (14).

Contact of blood with artificial surfaces of the extracorporeal circuit, ischemia-reperfusion injury, and release of endotoxin cause an inflammatory response in cardiopulmonary bypass. This inflammation process activates various systems such as, free radicals by polymorphonuclear neutrophils, leucocytes, and endothelial cells with secretion of cytokines, arachidonic acid metabolites and proteases. This inflammatory response plays an important role in major organ dysfunction (15).

Corticosteroids application to the children undergoing congenital heart surgery to reduce the inflammatory response after cardiopulmonary bypass is still a controversial process within the literature (16). Cardiopulmonary bypass is known to result in the release of inflammatory mediators, such as cytokines, by causing complement and leukocyte activation $(17,18)$. These mediators contribute to pulmonary and cardiac dysfunctions developed after cardiac surgery (19). The present study demonstrated that TNF- $\alpha$ levels were increased after two hours of the termination of the cardiopulmonary bypass with patients who did not receive steroid preoperatively and showed a peak at Post TNF- $\alpha$ Moreover, increases in the plasma levels were observed to continue at the postoperative $24^{\text {th }} \mathrm{h}$. TNF- $\alpha$ is a primary mediator of septic shock and is released from activated monocytes and macrophages. TNF- $\alpha$ is known to cause fever, tachycardia, hypotension and increase in microvascular permeability. Additionally, TNF- $\alpha$ has impacts on the multiple organ failure and myocardial dysfunction and its release is enhanced during cardiopulmonary bypass procedure due to ischemia-reperfusion, endotoxin release, and complement activa- 
tion (20). In the present study, TNF- $\alpha$ level was observed to be lower at patients who received steroid preoperatively as compared to other Group, and the duration of mechanical ventilatory support was shorter in received steroid Group. Systemic inflammatory response is triggered by cardiac and pulmonary reperfusion rather than cardiopulmonary bypass itself. Indeed, leukocytes are known to accumulate in coronary and vascular beds during cardiac procedures performed under cardiac arrest $(21,22)$. Additionally, adhesion and activation of leukocytes are facilitated due to stationary blood flow. Removal of aortic cross-clamp leads activated leukocytes to permeate to the organs through the systemic circulation and thus systemic inflammatory response occurs. Cardiac surgery is associated with endotoxemia and a marked inflammatory response. Therefore, endotoxin must be regarded as a pathophysiologic mediator. The endotoxin levels were higher after induction of anaesthesia, immediately after the start of cardiopulmonary bypass and after release of the cross-clamp (23). However in our study in group 2 at the second and third period also shows significant change of inflammatory mediators. Additionally in third period (post TNF- $\alpha$ ) statically significant $p(0.003)$.

Systemic inflammation and mechanical ventilatory support are known to potentiate the effects of each other (24). Short extubation avoids; i) the effects of positive pressure ventilation on the cardiopulmonary surgery, ii) ventilator-acquired pneumonias, iii) patient or parental stress in children, relative to long extubation (25). The present study, a significant difference was determined between both groups I and II in terms of time to extubation, which indicated that time to extubation postoperatively was significantly shortened with the preoperative steroid use. Based on this result, we believe that preoperative steroid use may shorten duration of entubation time.

In the current study, we concluded that preoperative steroid use might prevent potential changes in TNF- $\alpha$ level and minimize respiratory problems likely to develop in the postoperative period.

In conclusion, there is a strong indication that preoperative steroid use shortens duration of postoperative intubation and positively contributes to extubation in ventricular septal defect patients undergoing cardiac surgery with cardiopulmonary bypass. Additionally, this process is more closely associated with suppressing at the postoperative period TNF- $\alpha$ level which are inflammatory mediators.

\section{Limitations}

Complex heart disease or excessive pulmonary hypertension cases are excluded in this study. It is clear that various studies which include complex cases are needed to evaluate the effects of Steroid. The steroid response could better evaluate with other inflammatory markers in larger groups.
Ethics Committee Approval: Ethics committee approval was received for this study from the ethics committee of Çukurova University School of Medicine.

Informed Consent: Written informed consent was obtained from patients' parents who participated in this study.

Peer-review: Externally peer-reviewed.

Author contributions: Concept - H.H.P., Z.D.; Design - Ş.D., M.K.A.; Supervision - Ş.D., M.K.A.; Resource - M.K.A., A.A., B.Ç.; Materials - A.A., B.Ç.; Data Collection and/or Processing M.K.A., A.A., B.Ç.; Analysis and/or Interpretation - A.A., B.Ç.; Literature Search - H.H.P., Z.D.; Writing - İ.B., F.T., H.H.P.; Critical Reviews - H.H.P., Z.D., Ş.D.

Conflict of Interest: No conflict of interest was declared by the authors.

Financial Disclosure: The authors declared that this study has received no financial support.

\section{REFERENCES}

1. Pasquali SK, Hall M, Li JS, Peterson ED, Jaggers J, Lodge AJ, et al. Corticosteroids and outcome in children undergoing congenital heart surgery: analysis of the Pediatric Health Information Systems database. Circulation 2010;122:2123-30. [CrossRef]

2. Haddad R, El-Hassan D, Araj A, Hallal A, Abdelnoor AM. Some inflammation related parameters in patients following normo and hypothermic cardio-pulmonary bypass. ImmunopharmacoIImmunotoxicol. 2001;23:291-302. [CrossRef]

3. Annane D, Bellissant E, Cavaillon JM. Septic shock. Lancet 2005;365:63-78. [CrossRef]

4. Kats S, Schönberger JP, Brands R, Seinen W, van Oeveren W. Endotoxin release in cardiac surgery with cardiopulmonary bypass: pathophysiology and possible therapeutic strategies. Eur $J$ Cardiothorac Surg 2011;39:451-8. [CrossRef]

5. Bronicki RA, Backer CL, Baden HP, Mavroudis C, Crawford SE, Green TP. Dexamethasone reduces the inflammatory response to cardiopulmonary bypass in children. Ann Thorac Surg 2000;69:1490-5. [CrossRef]

6. Soltani G, Abbasi Tashnizi M, Moeinipour AA, Ganjifard M, Esfahanizadeh J, Sepehri Shamloo A, et al. Comparing the effect of preoperative administration of methylprednisolone and its administration before and during surgery on the clinical outcome in pediatric open heart surgeries. Iran Red Crescent Med J 2013;15:483-7. [CrossRef]

7. Rinder CS, Bonan JL, Rinder HM, Mathew J, Hines R, Smith BR. Cardiopulmonary bypass induces leukocyte-platelet adhesion. Blood 1992;79:1201-5.

8. Varan B, Tokel K, Mercan S, Dönmez A, Aslamaci S. Systemic inflammatory response related to cardiopulmonary bypass and its modification by methylprednisolone: high dose versus low dose. Pediatr Cardiol 2002;23:437-41. [CrossRef] 
9. Steinberg JB, Kapelanski DP, Olson JD, Weiler JM. Cytokine and complement levels in patients undergoing cardiopulmonary bypass. J Thorac Cardiovasc Surg 1993;106:1008-16.

10. Allan CK, Newburger JW, McGrath E, Elder J, Psoinos C, Laussen PC, et al. The relationship between inflammatory activation and clinical outcome after infant cardiopulmonary bypass. Anesth Analg 2010;111:1244-51. [CrossRef]

11. Franke A, Lante W, Fackeldey V, Becker HP, Thode C, Kuhlmann WD, et al. Proinflammatory and anti-inflammatory cytokines after cardiac operation: Different cellular sources at different times. Ann Thorac Surg 2002;74:363-71. [CrossRef]

12. Noronha IL, Niemir Z, Stein H, Waldher R. Cytokines and growth factors in renal disease. Nephrol Dial Transplant 1995; 10:775-86.

13. Randolph AG, Wypij D, Venkataraman ST, Hanson JH, Gedeit $\mathrm{RG}$, Meert KL, et al. Effect of mechanical ventilator weaning protocols on respiratory outcomes in infants and children: a randomized controlled trial. JAMA 2002;288:2561-8. [CrossRef]

14. Wan S, LeClerc JL, Vincent JL. Cytokine responses to cardiopulmonary bypass: lessons learned from cardiac transplantation. Ann Thorac Surg 1997;63:269-76. [CrossRef]

15. Bourbon A, Vionnet M, Leprince P, Vaissier E, Copeland J, McDonagh $\mathrm{P}$, et al. The effect of methylprednisolone treatment on the cardiopulmonary bypass-induced systemic inflammatory response. Eur J Cardiothorac Surg 2004;26:932-8. [CrossRef]

16. Graham EM, Atz AM, Butts RJ, Baker NL, Zyblewski SC, Deardorff RL, et al. Standardized preoperative corticosteroid treatment in neonates undergoing cardiac surgery: results from a randomized trial. J Thorac Cardiovasc Surg 2011;142:1523-9. [CrossRef]

17. Casey LC. Role of cytokines in the pathogenesis of cardiopulmonary induced multisystem organ failure. Ann Thorac Surg 1993;56:S92-S6. [CrossRef]
18. Clarizia NA, Manlhiot C, Schwartz SM, Sivarajan VB, Maratta R, Holtby HM, et al. Improved outcomes associated with intraoperative steroid use in high-risk pediatric cardiac surgery. Ann Thorac Surg 2011;91:1222-7. [CrossRef]

19. Tennenberg SD, Bailey WW, Cotta LA, Brodt JK, Solomkin JS. The effects of methylprednisolone on complement-mediated neutrophil activation during cardiopulmonary bypass. Surgery 1986;100:134-41.

20. Ohkawa F, Ikeda U, Kanbe T, Kawasaki K, Shimada K. Effects of inflammatory cytokines on vascular tone. Cardiovasc Res 1995;30:711-5. [CrossRef]

21. Ito H, Hamano K, Gohra H, Katoh T, Fujimura Y, Tsuboi H, et al. Relationship between respiratory distress and cytokine response after cardiopulmonary bypass. Surg Today 1997;27:2205. [CrossRef]

22. Ritter LS, Copeland JG, McDonagh PF. Fucoidin reduces coronary microvascular leukocyte accumulation early in reperfusion. Ann Thorac Surg 1998;66:2063-72. [CrossRef]

23. Boelke E, Storck M, Buttenschoen K, Berger D, Hannekum A. Endotoxemia and mediator release during cardiac surgery. Angiology 2000;51:743-9. [CrossRef]

24. Zupancich E, Paparella D, Turani F, Munch C, Rossi A, Massaccesi $\mathrm{S}$, et al. Mechanical ventilation affects inflammatory mediators in patients undergoing cardiopulmonary bypass for cardiac surgery: a randomized clinical trial. J Thorac Cardiovasc Surg 2005;130:378-83. [CrossRef]

25. Akhtar MI, Hamid M, Minai F, Wali AR, Anwar-ul-Haq, AmanUllah M, et al. Safety profile of fast-track extubation in pediatric congenital heart disease surgery patients in a tertiary care hospital of a devoloping country: An observational prospective study. J Anaesthesiol Clin Pharmacol 2014;30:355-9. [CrossRef] 